\title{
TECNOLOGIAS DIGITAIS E ORIGAMI NA FORMAÇÃO DOCENTE PARA O ENSINO DE GEOMETRIA NOS ANOS ESCOLARES INICIAIS
}

\author{
DIGITAL TECHNOLOGIES AND ORIGAMI IN TEACHER EDUCATION FOR \\ TEACHING GEOMETRY IN THE ELEMENTARY SCHOOL
}

\author{
José Kemeson da Conceição Souza \\ Secretaria Municipal de Educação de Marabá - PA \\ kemeson_18@yahoo.com.br \\ France Fraiha-Martins \\ Universidade Federal do Pará - UFPA \\ francefraiha@yahoo.com.br
}

\section{Resumo}

Esta pesquisa narrativa trata sobre formação continuada em contexto de trabalho, desenvolvida com um grupo de professores que ensinam matemática nos anos iniciais do ensino fundamental. Objetivamos compreender os aspectos formativos, mediado por Origami e Tecnologias Digitais, que contribuem para novas percepções docentes sobre o ensino de Geometria. Desenvolvemos um design de formação inspirado na teoria histórico-cultural de Vigotski e na pedagogia históricocrítica de Demerval Saviani, sistematizado em cinco momentos: experiência de vida e formação sensibilização para (auto) formação - materialização teórico-prática - sistematização do aprendizado - socialização. Utilizamos questionário, diário de formação, memoriais reflexivos, registros audiovisuais e entrevista. A Análise Textual Discursiva foi utilizada como metodologia para análise qualitativa. Os resultados revelam que: i) houve desenvolvimento do conhecimento específico do conteúdo, facilitado pelas tecnologias envolvidas, indicando que os motivos que levavam os professores a trabalharem de maneira limitada residiam na compreensão reducionista que possuíam sobre o conteúdo geométrico; ii) quando envolvidos em processo de interação mediado por uma pessoa mais experiente e por recursos didáticos capazes de proporcionarem estudo, discussão e reflexão do objeto matemático, as aprendizagens ocorrem satisfatoriamente. Ademais, a formação continuada deve ser desenvolvida de forma colaborativa e participativa, considerando os docentes como agentes importantes que são desse processo.

Palavras-chave: Ensino de Geometria. Origami. Tecnologias Digitais. Formação de Professores. Anos iniciais.

\begin{abstract}
This narrative research deals with continuing education developed with a group of teachers, who teach mathematics in the early years of elementary school, in a work context. We aim to understand the formative aspects, mediated by Origami and Digital Technologies, which contribute to new perceptions about the teaching of geometry. We developed a formation design inspired by Vygotsky historical-cultural theory and Demerval Saviani historical-critical pedagogy, systematized in five moments: life experience and formation - awareness for (self) formation - theoretical-practical
\end{abstract}


materialization - systematization of learning - socialization. We used a questionnaire, diary, reflective memorials, audiovisual records and interviews. Discursive Textual Analysis was used as a methodology for qualitative analysis. The results reveal that: i) there was a development of specific knowledge of content, facilitated by the technologies involved, indicating that the reasons that led teachers to work in a limited way were their reductionist understanding of geometric; ii) when involved in an interaction process mediated by a more experienced person and by didactic resources capable of providing study, discussion and reflection of the mathematical object, the learning occurs satisfactorily. In addition, continuing education should be developed in a collaborative and participatory manner, considering teachers as important agents of this process.

Keywords: Geometry Teaching. Origami. Digital Technologies. Teacher Education. Elementary School.

\section{INTRODUÇ̃̃O}

Constituir-se professor dos anos escolares iniciais, em especial para ensinar matemática, num mundo marcado pelos avanços tecnológicos é, nos termos manifestados por Prado (2013), apropriar-se de recursos comunicacionais e saber utilizá-los de modo crítico, fazendo escolhas adequadas à sua prática educativa e aos contextos de seus alunos. Além disso, a autora destaca a importância de professores se envolverem em espaços formativos mediados pelas tecnologias digitais, que possibilitem práticas e estudos colaborativos, a fim de tornarem-se sujeitos coletivos frente à sociedade atual marcada pela multidimensionalidade, incertezas e desafios constantes. Isto porque o trabalho colaborativo pode constituir-se um modo eficaz dos professores enfrentarem esses desafios e resolverem os problemas da profissão.

A formação continuada de professores da Educação Básica é um dos grandes desafios da atualidade, a formação precisa ser analisada, reavaliada, redimensionada. Nem todas as escolas possuem boa infraestrutura, e algumas delas encontram-se dentro de condições sociais, políticas, econômicas e culturais contraditórias, envolvidas em complexas relações que se estabelecem em seu interior. Com isso, é necessário que o profissional da educação possa refletir criticamente a respeito das demandas sociais, de sua função nesse contexto e da necessidade de formação contínua ao longo de sua carreira profissional, uma vez que a formação de professores deve ser compreendida a partir da ideia de continuidade, de incompletude. (FREIRE, 1996).

Para Imbernón (2011, p.72), a formação permanente do professor deve "ajudar a desenvolver um conhecimento profissional que the permita avaliar a necessidade potencial e a qualidade da inovação educativa que deve ser introduzida constantemente nas instituições". O autor ainda destaca que a formação permanente do professor deve 
"proporcionar as competências para serem capazes de modificar as tarefas educativas continuamente, em uma tentativa de adaptação à diversidade e ao contexto dos alunos" (IMBERNÓN, 2011, p.72).

Nessa perspectiva, é necessário pensar em processos formativos que permitam aos docentes que "examinem suas teorias implícitas, seus esquemas de funcionamento, suas atitudes [...] realizando um processo constante de autoavaliação que oriente seu trabalho" (IMBERNÓN, 2011, p.51). Ademais, pensar em uma formação que atenda as necessidades dos professores é pensar numa proposta de formação com os professores e não para os professores (IMBERNÓN, 2011). Compreendemos, ainda, que a formação docente deve estar pautada em uma concepção de educação voltada à interação, ao respeito, à história e à cultura do principal agente nesse processo de formação, o professor. Nesse sentido, consideramos pertinente a pedagogia histórico-crítica, defendida por Saviani (1992), como concepção educacional para pensar a formação continuada de professores.

$\mathrm{O}$ ato de ensinar possui papel fundamental para o desenvolvimento e aprendizagem significativa. Por isso é importante que o professor se faça alguns questionamentos, como: Para que ensinar determinado conteúdo? O que ensino sobre esse conteúdo? Como ensino? Por que ensino desse modo? Ao se questionar, surge o problema da transformação do saber elaborado em saber escolar. Para Saviani (1992, p.79), “essa transformação é o processo através do qual se selecionam, do conjunto do saber sistematizado, os elementos relevantes para o crescimento intelectual dos alunos e se organizam esses elementos numa forma, numa sequência tal qual possibilite a sua assimilação".

Portanto, a formação continuada de professores apresenta grande relevância, principalmente, para os professores que atuam no primeiro segmento do ensino fundamental, pois em geral são profissionais licenciados em Pedagogia, curso este que, por dar ênfase às várias áreas, incluindo os conhecimentos pedagógicos e de gestão escolar, nem sempre durante a formação alcança de maneira satisfatória os conhecimentos específicos da educação matemática (SANTOS; NACARATO, 2014).

No contexto do ensino de geometria nos anos escolares iniciais, concordamos com Fiorentini e Miorin (1996) que a Geometria possibilita desenvolvimento do pensamento lógico e a compreensão do ambiente que vivemos. O estudo da Geometria propicia o desenvolvimento do raciocínio lógico matemático. Permite a evolução da aprendizagem, partindo do reconhecimento de elementos matemáticos existentes no mundo físico, os 
quais podemos perceber através dos sentidos, e encaminhar para a nossa imaginação, facilitando a abstração dos objetos matemáticos, bem como objetos de outras áreas do conhecimento. Pavanello (2004) diz que a geometria pode ser entendida como um campo proveitoso para o desenvolvimento da capacidade de abstrair, generalizar e projetar o que é sensível.

Contudo, pesquisas como de Bagé (2008), Costa (2008) e Rodrigues (2009) que investigaram processos de formação continuada de professores que atuam nos anos iniciais, no âmbito do ensino de geometria, indicam que os professores investigados tinham poucos conhecimentos dos conteúdos de Geometria, mesmo com a formação em nível superior. A falta de conhecimentos não era apenas relativa aos conteúdos matemáticos, mas também associada aos conhecimentos didáticos e curriculares relativos à geometria. Revelaram ainda, que apesar do ensino de Geometria ser contemplado em documentos oficiais e nos currículos escolares, ele ainda não se efetivou como uma proposta mais significativa. Os resultados permitiram sugerir que os cursos de formação inicial e continuada para professores do Ensino Fundamental devam oferecer um ensino crítico de conceitos geométricos, a fim de que os professores adquiram formação profissional mais especializada para esse nível de ensino, de modo a desenvolver conhecimentos aprofundados e socialmente úteis sobre conteúdos de Geometria.

Diante dessas questões, elaboramos um curso de formação continuada pautado na Pedagogia Histórico-Crítica de Saviani (1992), por ser um dos autores que sustentam a proposta curricular de vários municípios da nossa região e por apresentar cinco passos que contribuem para a prática docente no âmbito de educação matemática crítica para os anos iniciais do ensino fundamental. Além da perspectiva histórico-crítica, pautamo-nos em Vigotski (1998) para defender uma proposta de formação (docente ou discente) que tenha como base a interação entre os sujeitos - professor $\mathrm{x}$ aluno, aluno $\mathrm{x}$ aluno - pois é a partir dessas interações que os sujeitos envolvidos nesse processo poderão por intermédio do outro compreender, aprender, inferir e adquirir novos conhecimentos e percepções, desenvolvendo-se histórico e socialmente.

Privilegiamos nessa pesquisa uma proposta de formação que foi desenvolvida com professores que ensinam Matemática no $4^{\circ}$ e $5^{\circ}$ ano do Ensino Fundamental, ocorrida na própria escola onde atuam (em contexto de trabalho). Os docentes utilizaram tecnologias digitais e origami para aprimoramento do conteúdo de Geometria e seu ensino, bem como 
discussão e reflexão sobre os processos e resultados dos momentos formativos realizados. Sendo assim, sistematizamos a seguinte pergunta de pesquisa: Que aspectos formativos, em um curso de Formação Continuada, mediado por Origami e Tecnologias Digitais, contribuem para outras/novas percepções docentes sobre o ensino de Geometria nos anos iniciais do Ensino Fundamental?

Para responder essa questão, lançamos mão de algumas perguntas norteadoras: Que ideias os professores expressam sobre o ensino de Geometria nos anos iniciais? O que expressam sobre o uso associado do origami e das tecnologias digitais para o ensino de Geometria? Que percepções docentes são construídas sobre a experiência formativa vivenciada? Objetivamos nesta pesquisa compreender aspectos formativos em um curso de formação continuada que contribuem para outras/novas percepções docentes. Buscamos estabelecer relações entre os conhecimentos desejáveis para ensinar geometria nos anos iniciais e a formação de professores que ensinam matemática, a fim de propiciar processos reflexivos quanto à necessidade do conhecimento específico do conteúdo, bem como de metodologias diferenciadas de ensino desse conteúdo.

\section{ANUNCIANDO AS OPÇÕES METODOLÓGICAS DA PESQUISA}

Esta é uma investigação qualitativa, na modalidade narrativa ${ }^{1}$. Para Deslauriers e Kérisit (2008), a pesquisa qualitativa centra-se na subjetividade do fenômeno, no que está explícito e implícito, dando ênfase aos sujeitos envolvidos e ao contato direto com o campo de pesquisa. Portanto, o pesquisador qualitativo se justifica por produzir proposições de caráter exemplar e único de amostras não probabilísticas que dá acesso a um conhecimento detalhado e circunstancial da vida social (DESLAURIERS e KÉRISIT, 2008).

Assumimos a narrativa como método de pesquisa pela capacidade de transmitir significados, pois seu processo de produção "requer uma reconstrução da experiência de uma pessoa [ou de pessoas] em relação aos outros e ao ambiente social" em que está inserida (CLANDININ e CONNELLY, 2011, p. 73). Ou seja, o pesquisador, ao narrar os fatos por meio da percepção do sujeito em relação a ele próprio e aos outros no contexto

\footnotetext{
${ }^{1}$ Este artigo é recorte da pesquisa mais ampla: SOUZA, J. K.C. Percepções Docentes sobre o Ensino e Aprendizagem de Geometria nos Anos Iniciais do Ensino Fundamental: reflexos e reflexões de uma experiência formativa. Dissertação (Mestrado em Programa de Pós-Graduação em Docência em Educação em Ciências e Matemáticas) - Universidade Federal do Pará. 2018.
} 
investigado - integrando a essa narrativa interpretação própria à luz da teoria assumida produz uma nova narrativa, uma nova percepção, um novo sentido.

A pesquisa ocorreu em uma escola municipal de ensino fundamental na cidade de Marabá, estado do Pará, pelo fato de um de nós (autores) sermos vinculados à secretaria de educação desse município, na condição de membro de uma equipe de formadores de professores da rede municipal que conduz processos de formação continuada de professores que ensinam matemática nos anos iniciais do fundamental. Em termos dos participantes dessa pesquisa, são 04 professores-alunos investigados, os quais participaram do processo de formação continuada em contexto de trabalho: Favo de mel, Girassol, Junina e $\mathrm{Cobra}^{2}$ (nomes fictícios). Esses quatro professores compõem a totalidade de docentes que lecionam no $4^{\circ}$ e $5^{\circ}$ ano no contexto escolar em estudo.

Nessa perspectiva, para a produção do material empírico lançamos mão de vários instrumentos de investigação a fim de obter o máximo de informações. São eles: questionário com a finalidade de obter informações de cunho pessoal e profissional; os memoriais reflexivos que os professores escreveram ao final do processo formativo; os registros audiovisuais dos encontros; e entrevista semiestruturada com foco a extrair informações que em algum momento ficou de difícil compreensão.

Para tratar e analisar os textos de campos e construir o metatexto narrativo (CLANDININ; CONNELLY, 2011), utilizamos a Análise Textual Discursiva (MORAES; GALIAZZI, 2011) como metodologia para análise dos dados, numa busca de interpretar e construir novas compreensões sobre as narrativas dos professores-alunos envolvidos. Conforme Moraes e Galiazzi (2011), a Análise Textual Discursiva (ATD) inicia com a desmontagem dos textos de campo em busca de unidades de significados. Segue com o estabelecimento de relações entre os focos de sentidos recorrentes expressos pelos sujeitos investigados, além de dar destaques às singularidades relevantes, de modo a captar o novo emergente. Por fim, esse processo auto organizativo vai dando forma as categorias analíticas que buscam responder a questão principal de pesquisa.

Nesses termos, sistematizamos duas grandes categorias de análise emergentes, a saber: EXPERIÊNCIAS DE VIDA E FORMAÇÃO COM A GEOMETRIA: da educação

\footnotetext{
${ }^{2}$ Nomes atribuídos pelos professores-alunos as suas próprias obras criadas com formas geométricas em EVA no primeiro encontro do processo formativo em análise.
} 
básica e formação inicial à prática docente; e ORIGAMI E TECNOLOGIAS DIGITAIS: instrumentos mediadores para o ensino e aprendizagem de geometria. Passamos a descrever o processo de formação realizado com os professores, explicitando as etapas desenvolvidas no design de formação elaborado e vivenciado.

\section{FORMAÇÃO CONTINUADA EM CONTEXTO DE TRABALHO: geometria e seu ensino nos anos iniciais}

O design de formação desenvolvido foi inspirado na concepção de formação permanente defendida por Imbernón (2011) e nos cinco passos sugeridos para pedagogia histórico-crítica por Saviani (1992) e tratados didaticamente por Gasparin (2002) ${ }^{3}$. O design de formação desenvolvido está sistematizado em cinco momentos: 1) Experiência de Vida e Formação (apresentação da proposta + narrativas de professores); 2) Sensibilização para (Auto) Formação (reflexão sobre a ação + estudos e discussões de textos); 3) Materialização Teórico-Prática (uso de tecnologias digitais + manipulação de origami); 4) Sistematização do Aprendizado (elaboração de sequência de ensino + escrita de memorial reflexivo); 5) Socialização (planejamento + significados da experiência formativa).

O primeiro momento do design formação, denominado EXPERIÊNCIAS DE VIDA E FORMAÇÃO, constituiu-se da apresentação da proposta formativa aos professores-alunos, que poderiam optar ou não em participar do processo formativo. Este foi um momento de conquista e de aproximação primeira. Após a apresentação da proposta e possíveis negociações/ajustes da intenção inicial, foi solicitado aos professores-alunos que escrevessem narrativas de si. Nesse documento, indicamos algumas perguntas orientadoras de cunho pessoal e profissional, além de questões voltadas ao objeto a ser estudado, nesse caso, a geometria.

Essa dinâmica objetivou conhecer um pouco mais cada professor sobre suas crenças, dificuldades e necessidades formativas, em especial, sobre sua relação com a Geometria e perspectivas do processo formativo a ser vivenciado. Esse instrumento foi fundamental para planejar as outras ações da formação.

\footnotetext{
${ }^{3}$ Gasparin (2002), no livro "uma didática para a pedagogia histórico-crítica", apresenta cinco passos com a finalidade de tornar a pedagogia histórico-crítica mais didática.
} 
$\mathrm{Na}$ sequência, ocorreu a problematização que objetivou "detectar que questões precisam ser resolvidas no âmbito da prática social e, em consequência, que conhecimento é necessário dominar" (GASPARIN, 2002, p. 35). O autor esclarece que é uma das etapas fundamentais do processo de ensino e aprendizagem por ser um elemento chave na transição entre teoria e prática, isto é, entre o fazer cotidiano e a cultura elaborada. É quando se inicia o trabalho com o conteúdo sistematizado. No momento em que os professores narram suas experiências, o processo de problematização acontece.

O segundo momento formativo, SENSIBILIZAÇÃO PARA (AUTO)FORMAÇÃO, foi privilegiada a instrumentalização, levando-os à aproximação de instrumentos teóricos no âmbito da docência a fim de auxiliá-los na construção de argumentos/conhecimentos em torno da (auto)formação. Processos de estudos e discussão de textos que pudessem provocar a necessidade de refletir e pesquisar sobre a própria prática, de se tornar professor reflexivo e de compreender as teorias que subsidiam as práticas docentes. "Se estamos indo, é bom que saibamos para onde". Foi nesse momento que o conteúdo sistematizado esteve à disposição para que pudesse ocorrer a aprendizagem do conhecimento matemático. Nessa etapa, com a ajuda do professor-formador o professoraluno pôde apropriar-se do conhecimento social e historicamente produzido.

No terceiro momento do processo formativo, MATERIALIZAÇÃO TEÓRICOPRÁTICA, demos continuidade ao passo da instrumentalização, agora mediado pelos recursos pedagógicos: as Tecnologias Digitais e o Origami. Nessa etapa da instrumentalização a teoria e a prática ocorreram de forma integrada. Sistematicamente, os professores-alunos realizaram as dobraduras no papel para a confecção do origami. Isto é, para cada dobra feita, alguns questionamentos eram realizados, postos em discussão e, seguidos de pesquisas na internet em sites previamente selecionados em busca de respostas. Após a pesquisa e a consolidação da noção daquele conceito que surgiu com a dobra realizada, os professores-alunos passavam a representar a etapa (dobra) no Geogebra ${ }^{4}$. Por fim, os professores acessaram via celular os vídeos ${ }^{5}$ que demonstravam como construir os poliedros.

\footnotetext{
${ }^{4} \mathrm{O}$ software Geogebra foi criado em 2001 por Markus Hohenwarter, como sendo um programa de computador de acesso livre sendo utilizado em diversos níveis de assuntos matemáticos que tem como objetivo fazer com que o estudo da Matemática se torne mais dinâmico e facilitado (PAIVA, 2012).

${ }^{5}$ Esses vídeos foram elaborados por um dos autores. Neles, apresenta-se o passo a passo de como construir os poliedros de Platão por meio de dobraduras.
} 
O quarto momento do processo formativo, denominado SISTEMATIZAÇÃO DO APRENDIZADO, foi o momento em que os professores colocaram em prática o que aprenderam nas etapas anteriores por meio da elaboração de uma sequência de ensino a ser desenvolvida com os seus alunos. Além disso, escreveram sobre suas aprendizagens matemáticas na forma de memorial reflexivo ${ }^{6}$ ocorridas no âmbito da formação em ação.

O quinto e último momento do design de formação, a SOCIALIZAÇÃO, constituiu-se do movimento de novas/outras ideias sobre as práticas de ensino de matemática, em especial de geometria, pelos professores-alunos. Nesse momento, os professores-alunos socializaram os seus planejamentos construídos para o ensino de geometria a partir das aprendizagens desenvolvidas por eles durante o processo formativo; relataram sobre as novas/outras ideias de práticas pedagógicas; e os conhecimentos adquiridos por meio do design de formação vivenciado.

Enfim, o design descrito aqui, sinteticamente, buscou propiciar a troca de experiências entre os pares, dando voz aos professores-alunos e construindo uma proposta de formação com eles e não para eles. Passamos a seguir às discussões advindas das análises que emergiram do processo investigativo.

\section{EXPERIÊNCIA DE VIDA E FORMAÇÃO COM A GEOMETRIA: da educação básica e formação inicial à prática docente}

As experiências evidenciadas pelos professores-alunos expressam sobre o (não) contato com Geometria na educação básica ou na graduação. É possível inferir que algumas lacunas existentes e manifestadas pelos professores que ensinam matemática nos anos iniciais ocorrem pelo fato deles não terem estudado geometria nesses níveis de ensino, ou estudado de modo superficial. Como ensinar algo que não sabe?

A Geometria é o instrumento que o ser humano encontra para transformar e representar o espaço em que vive. Pode a partir dela, planejar e construir objetos, definir, opinar e exprimir ideias percebidas no ambiente e representar o mundo em linguagem científica. Nesse contexto, Soares (2009, p.96) aponta que "a geometria é essencialmente humana, ou um conjunto de criações". Na escola, as crianças devem fazer uso da Geometria para desenvolver seu pensamento criativo, sua capacidade de visualização espacial, bem

\footnotetext{
${ }^{6}$ Para a escrita do memorial reflexivo, alguns textos poderão ser utilizados para ajudar os professores-alunos nesse processo.
} 
como desenvolver sua comunicação a partir das relações espaciais entre os objetos. O desafio é fazer com que o ensino de geometria proporcione aos alunos tais aprendizagens. Para Soares (2009) o grande objetivo do ensino da Geometria é fazer com que as crianças passem do espaço vivenciado para o espaço pensado.

De acordo com o Lorenzato (1995, p. 04), os livros didáticos apresentam a Geometria como um conjunto de definições, propriedades, nomes e fórmulas, “desligado de quaisquer aplicações ou explicações de natureza histórica ou lógica". Este argumento é possível ser percebido nas falas dos professores-alunos, que vivenciaram o processo formativo. Ao Indagarmos sobre sua aprendizagem da Geometria na Educação Básica a professora Junina nos aponta que em relação à Geometria não tem muitas lembranças desse conteúdo na Educação Básica. Diferente do Professor Cobra que se lembra de ter visto e estudado Geometria, no entanto, de forma superficial: quanto ao aspecto da geometria, lembro-me de ter visto no ensino médio e sem muita ênfase (pelo menos é o que lembro). Também aconteceu com a Professora Favo de Mel, quando diz que: tive uma relação sem muito aprofundamento, lembro-me vagamente dos conteúdos e das dificuldades que tive.

Os quatro professores que participaram da investigação narraram não terem estudado, em sua Educação Básica, a Geometria ou quando estudaram a fizeram de forma superficial, como nos relatou a Professora Favo de mel. Alguns docentes sequer estudaram em sua graduação, como nos relata a docente Girassol: durante a Educação Básica estudei, sim, geometria, porém minha relação com a matemática não foi muito boa, então não tenho muitas lembranças desse conteúdo. Na graduação não estudei geometria.

Enquanto a professora Girassol nos narra que não estudou nenhum conteúdo da Geometria na Graduação, a docente Favo de Mel relata que estudou metodologias para ensinar Matemática: na graduação estudei apenas sobre a metodologia do ensino da Matemática.

As falas das Professoras Favo de Mel e Girassol nos leva ao que Santos e Nacarato (2014) apontam:

Sabemos que apenas um curso de Fundamentos e Metodologia do Ensino de Matemática - que existe na maioria dos cursos de Pedagogia - não é suficiente para um trabalho mais conceitual com os futuros professores, pois, geralmente, essa disciplina acaba centrando nos conteúdos do sistema de numeração decimal e nas quatro operações. Além disso, muitos desses cursos nem trazem Geometria nas suas ementas (SANTOS; NACARATO, 2014, p. 10)

Os cursos em Pedagogia são geralmente voltados à formação com ênfase em 
conhecimento pedagógico e de gestão escolar, deixando, por muitas vezes, de contemplar conhecimentos de áreas específicas, haja vista que uma das possibilidades de atuação do profissional formado em Pedagogia é ser professor, que atuará nos anos iniciais do Ensino Fundamental. No entanto, não podemos dizer que são todos os cursos de Pedagogia que deixaram de propiciar o ensino de conteúdos específicos aos graduandos. O professor Cobra, por exemplo, não viu de forma satisfatória a Geometria na Educação Básica, mas suas lembranças o remetem ao preparatório para o vestibular e a oportunidade que teve de estudar quando fez sua graduação.

Quanto ao aspecto da geometria, lembro-me de ter visto no ensino médio sem muita ênfase. Porém, foi no preparatório para o vestibular que fui entender a geometria e na universidade compreender sua funcionalidade por intermédio do seu uso e sua viabilidade na arquitetura barroca e moderna. Entendo que a geometria esta ao nosso redor. Essa percepção vem sendo aprimorada nas formações continuadas às quais tive o privilégio de participar. (COBRA).

O professor Cobra faz parte de um grupo de professores que estudou Matemática/Geometria em sua graduação de modo satisfatório, no caso dele, não só estudou como passou a gostar da disciplina. As dificuldades que Cobra possui são as que quase todo professor polivalente apresenta, no entanto, tais dificuldades não o impede de ir em busca de outras fontes de aprendizagens, entre elas os cursos de Formação Continuada. Cobra reconhece que sua formação inicial deixou lacunas e por meio da Formação Continuada tem conseguido a cada dia compreender e perceber um pouco mais as nuances da Geometria, conforme expressa: quando eu comecei a participar de cursos de formação continuada, a minha visão sobre geometria ficou melhor. Na formação, a gente aprendeu a manipular a geometria. Cobra se remete a uma formação que recebeu em outro momento não a esta que ele estava participando.

Outro aspecto analítico refere-se às reflexões e transformações no entendimento dos docentes sobre o processo de ensino e aprendizagem de Geometria nos anos iniciais ao participarem da formação. Ao irem aprofundando a geometria, o autoconhecimento de que a ensinavam de forma reduzida veio à tona. A professora Junina, narra que possuía a visão docente de que os alunos precisariam apenas reconhecer as formas geométricas.

Percebi que ensinava a geometria achando que tinham apenas que reconhecer as formas geométricas tais como: quadrado, retângulo, círculo e outros. No entanto, a partir dessa formação, passei a compreender que a geometria vai muito além de identificar e nomear figuras. Percebi que temos a prática, mas falta o conhecimento específico para embasar nossas práticas. (JUNINA)

Mais do que perceber que o ensino de Geometria não se limita apenas ao 
reconhecimento das figuras geométricas, a professora Junina compreende que precisa de estudos mais aprofundados que possam lhe ajudar a desenvolver melhor as suas práticas pedagógicas. Assim como a professora Junina, a docente Girassol, que é a menos experiente na docência, isto é, possui menos tempo de atuação docente, também relata que entendia que ensinar geometria era apenas fazer com que os alunos conhecessem as formas geométricas. Para ambas as docentes a experiência formativa vivenciada proporcionou a construção de novos significados sobre o ensino de Geometria. Girassol nos conta que:

Eu gostei bastante da formação, porque eu pensava que ensinar geometria era trabalhar as formas geométricas (quadrado, triangulo, retângulo, etc.) e só. Como nunca havia trabalhado com $4^{\circ}$ e $5^{\circ}$ ano, essa é a primeira vez que vou trabalhar, eu não tinha muita noção do que eu deveria ensinar (GIRASSOL).

Girassol manifesta ter adquirido significativas aprendizagens. Inferimos isso pelo fato de que ela ainda não havia ensinado esse conteúdo em nenhum outro momento de sua carreira. Até então a professora só havia trabalhado com alunos menores (ciclo de alfabetização). Ademais, Girassol tinha poucos anos de docência.

Nessa perspectiva, os cursos de formação continuada não devem se limitar apenas às discussões teóricas sobre o como ensinar determinados conteúdos. Partimos do princípio de que a formação continuada deve iniciar pelas experiências dos professores-alunos e a reflexão sobre as práticas vivenciadas ao ensinar matemática, para daí ocorrerem discussões fundamentadas no que vivenciam. Acima de tudo, os momentos formativos devem servir para refletir sobre a própria prática. Sobre essa abordagem, a professora Girassol nos relata:

Percebi com a formação, que a geometria que eu pensei em trabalhar seria muito simples, pois eu não aprofundaria o conteúdo, ficaria vagando e mostrando o trivial. Entendi que devemos avançar e aprofundar o conhecimento desse conteúdo com os nossos alunos, realizando um bom planejamento e utilizando materiais que "catalisem" esse processo, isto é, que me ajudem e ajudem os alunos. (GIRASSOL)

Como dissemos anteriormente, a professora Girassol é a única do grupo que ainda não havia trabalhado com o conteúdo de Geometria. Ela evidencia que, se não tivesse participado desta formação continuada em questão, trabalharia de forma reducionista, apenas ensinando o reconhecimento e classificação das figuras, com o mesmo entendimento da professora Junina. Nesse sentido, a formação contribuiu para que a professora Girassol pudesse compreender que um bom planejamento subjaz uma boa prática. Assim, quando ela ministrar o conteúdo pela primeira vez, provavelmente, se 
sentirá mais segura e com uma visão diferenciada.

Resgatando a ideia de reflexão sobre a própria prática como um dos pilares que devem sustentar os cursos de formação continuada, o professor Cobra, que demonstrou inicialmente ser mais experiente, pôde refletir sobre suas experiências anteriores com a Geometria, sinalizando que julgava ministrar bem o conteúdo:

\begin{abstract}
Sempre gostei de ministrar a aula de geometria e imaginava que desenvolvia bem esse conteúdo. Contudo, percebi que preciso argumentar mais e melhorar os conceitos matemáticos para um bom entendimento dos alunos, e ter mais meios de mostrar na prática objetos manipulativos que facilitem a percepção e comparação do que se aprende na escola, com o que está presente em nossa volta e mostrar a real função social da disciplina matemática. (COBRA).
\end{abstract}

Somos seres inacabados como nos diz FREIRE (1996) e partindo desse pressuposto podemos a cada tempo aprender e desenvolver novas práticas, desde que estejamos abertos a aceitar críticas e o novo, assim como aconteceu com o professor Cobra, que mesmo com tantos anos de experiência não se fechou em uma "caixinha" e passou a entender que se argumentar mais em suas aulas poderá chamar ainda mais a atenção dos seus alunos, e que o desafio do ensino está em fazer com que o aluno compreenda que o conhecimento que é ensinado na escola pode ser utilizado em sua vida.

Nessa perspectiva, Lorenzato (1995) aponta que a Geometria está nas atividades humanas presentes no dia a dia e na natureza (caramujos, botões, favos e flores, abacaxis, etc.) e, portanto, nós professores precisamos proporcionar um ensino pautado na vivência, na experiência, na realidade em que os alunos estão inseridos.

Por meio da experiência vivenciada, os professores manifestaram alguns conhecimentos que ainda não detinham do conteúdo, como é o caso do professor Cobra que passa a compreender os conceitos dos elementos que compõem os poliedros de Platão, assim como também a empregar os termos científicos adequadamente. Sendo assim, a percepção de que o ensino de Geometria não pode ser resumido apenas ao reconhecimento de figuras planas e, que se deve utilizar outros materiais e recursos para propiciar o ensino e a aprendizagem de Geometria é, também, um dos novos significados construídos pelos professores.

\title{
ORIGAMI E TECNOLOGIAS DIGITAIS: instrumentos mediadores para o ensino e aprendizagem de geometria
}

O terceiro momento do design de formação, intitulado MATERIALIZAÇÃO 
TEÓRICO-PRÁTICA, aconteceu a partir da mediação dos seguintes recursos: as tecnologias digitais (computador, celular, vídeos, o software Geogebra e internet) e o Origami $^{7}$. A escolha em trabalhar com o origami se deu por este ser um recurso de fácil acesso, baixo custo e por poder fazer com que os alunos (professores) se familiarizem com formas geométricas, movimentos de transformação e múltiplas linhas de simetria dentro de uma mesma figura (RÊGO et al, 2003, p.18).

Nosso objetivo na condição de formadores era realizar junto com eles, paulatinamente, as dobras e suas representações no Geogebra até chegar à construção do poliedro. A cada dobra fazíamos um estudo sobre a noção matemática contida nela. Inserimos o editor de texto Word para a anotação dos procedimentos realizados (funcionou como uma espécie de "caderno de anotações"). Acrescentamos os sites, previamente selecionados, para que os professores-alunos pudessem fazer pesquisas buscando responder aos questionamentos feitos sobre algum elemento [geométrico] estudado ou para buscar o conceito/definição. Além disso, elaboramos vídeos para eles e os disponibilizamos no youtube, apresentando a construção dos poliedros a partir das dobraduras. A variedade de instrumentos/recursos se deu por compreendermos que quanto maior a variedade de recursos/instrumentos, maior a possiblidade de estímulos e de maneiras de estudar o objeto matemático, no intuito de alcançar o maior número de educandos em seus processos de aprendizagens (FRAIHA-MARTINS, 2014).

Sendo assim, durante o processo formativo, em linhas gerais, os professores-alunos eram convidados a elaborarem questionamentos e a pesquisarem na internet em busca de respostas. Em seguida, faziam a representação da dobra no Geogebra que já haviam feito no papel e depois realizavam as anotações no editor de texto Word.

Vários questionamentos foram produzidos de modo a subsidiar as discussões e o estudo. Dentre eles: O que podemos falar a respeito dessa figura? Quais são as características dessa forma? o que seria um cubo? E um poliedro? O que caracteriza um sólido geométrico? Qual a forma dessas faces? O que caracteriza tais faces? O que são vértices em um sólido geométrico? O que representa as arestas? Qual o formato da folha que vocês receberam e representaram no Geogebra? Quais as características desse polígono?

\footnotetext{
${ }^{7}$ Para saber mais sobre a proposta formativa desenvolvida, acesse o produto educacional disponível em https:/educapes.capes.gov.br/bitstream/capes/431468/2/Geometria\%20nos\%20Anos\%20Iniciais.pdf
} 
Ao realizarmos o corte, que forma obtivemos? Quais as diferenças e semelhança desse polígono para o primeiro que analisamos? Que considerações podemos fazer?

Com os questionamentos realizados e a mediação do formador, os professoresalunos puderam chegar a várias conclusões, por exemplo, de que todo quadrado é retângulo e losango. E assim foram sendo realizadas as atividades, fazendo a dobra, representando no Geogebra e discutindo cada novo elemento de Geometria que surgia até chegarmos à figura final, que representa uma face do poliedro (hexaedro). Sendo assim, os professores tiveram a oportunidade de manipular o origami e o Geogebra ao mesmo tempo, fazendo a associação com conceitos matemáticos pesquisados nos sites previamente estabelecidos.

Retomando as narrativas desse momento formativo com os professores, consideramos que as intervenções realizadas, com o auxílio do Geogebra e do Origami, contribuíram para que os professores chegassem ao conceito de mediatriz, que pode ser expresso na fala da professora Girassol: Ah! Então podemos dizer que a mediatriz é um segmento de reta que passa pelo ponto médio e, o ponto médio será um ponto que divide um segmento de reta em duas partes congruentes. [...] A utilização desses recursos me ajudaram a entender.

Nessa perspectiva, encontramos também na narrativa da professora Junina certa evidência de que as tecnologias digitais e o origami, usados como instrumentos mediadores, contribuíram para o aprofundamento das aprendizagens sobre o objeto matemático em estudo. Junina expressa:

foi uma experiência que levarei em minha memória para o resto da vida, pela construção dos significados, pelas atividades propostas que me permitiram refletir por meio de boas perguntas feitas pelo formador e que nos permitiram aprender de forma concreta e estruturada os conceitos e as técnicas. A sistematização que fizemos contribuiu para o processo de reflexão a que se referem os teóricos apresentados durante a formação. A proposta e a didática do formador foram pontos cruciais para entender e potencializar a construção do conhecimento matemático. (JUNINA)

É importante destacar que os conhecimentos matemáticos foram sendo aprofundados ao longo da formação. Ao fazermos uma discussão minuciosa sobre o polígono que forma o Hexaedro, o professor Cobra chega à seguinte conclusão: o quadrado é um polígono que possui quatro segmentos de retas com mesma medida (quatro lados iguais), quatro ângulos retos, duas diagonais e quatro eixos de simetria. Essa constatação foi feita a partir da manipulação do Origami. Eles tiveram que medir os lados, os ângulos e verificar os eixos de simetria para fazer tal afirmação. 
A professora Favo de mel, se expressa da seguinte forma:

a utilização dos recursos facilitaram o meu aprendizado. Esta formação aprofundou o pouco conhecimento que eu tinha de geometria. Não sabia trabalhar com estes materiais. Aprendi coisas que ainda não sabia, por exemplo, confeccionar alguns poliedros, defini-los. Isto certamente fará grande diferença em minha prática docente.

Um ponto importante para destacar na fala das professoras Junina e Favo de mel é o reconhecimento que o uso desses materiais pode ser fundamental no processo de ensinar e aprender, como reforçam Fiorentini e Miorim (1996) sobre a utilização de materiais manipulativos. A professora Girassol também considerou satisfatória sua participação no curso e de ter tido contato com os materiais utilizados, como narra: Os materiais que foram utilizados foram bem interessantes e adequados para os anos que estamos trabalhando. Esses materiais podem ser utilizados sem nenhum problema na sala de aula, desde que o professor planeje, organize e estude os materiais.

O objetivo não era o de levar apenas novas metodologias com tecnologias para que eles utilizem com seus alunos, mas desenvolvê-las explorando o conhecimento específico da matemática, de maneira tal que eles possam pensar sobre como desenvolver novas práticas, a fim de facilitar a compreensão dos seus alunos. Nossa intenção era de lançar desafios aos professores e propiciar aprendizagens, produzindo o significado de que as tecnologias digitais e o origami quando utilizados para ensinar figuras geométricas tornamse instrumentos mediadores e potencializadores da aprendizagem matemática.

Portanto, consideramos que os professores precisam se sentir motivados e coautores dos processos de formação continuada no contexto escolar. É desejável que eles vivenciem experiências diferenciadas de formação para buscar novas atividades a serem desenvolvidas em sala de aula. Sobretudo, para se apropriarem criticamente das linguagens e códigos multimídias e multidirecionais situadas por seus alunos, de modo a fazerem uso em aula como forma de aproximar-se dos interesses e das realidades dos educandos, a fim de motivá-los para a aprendizagem (FRAIHA-MARTINS, 2009).

\section{CONSIDERAÇÕES FINAIS}

A formação continuada, em contexto de trabalho, quando mediada por tecnologias digitais e o origami, pode proporcionar nos docentes envolvidos avanços na compreensão no/do processo de ensino e aprendizagem de Geometria nos Anos Iniciais do Ensino 
Fundamental. Pensar em uma proposta de formação é levar em consideração os conhecimentos já adquiridos previamente pelos professores-alunos sobre o objeto matemático a ser estudado.

É preciso perceber os seus anseios, necessidades, dificuldades, expectativas. Nesses termos, a formação continuada em contexto de trabalho deve ser pensada para ser desenvolvida de forma colaborativa e participativa. Os professores-alunos envolvidos deverão ser valorizados e respeitados como agentes importantes que são desse processo.

Nesses termos, a mediação e a interação são fundamentais para que os objetivos formativos sejam alcançados. Nesta pesquisa, consideramos o papel de mediação do professor-formador estratégico e eficiente, tanto para o engajamento dos participantes nas ações formativas quanto para as aprendizagens docentes manifestadas.

Na mesma perspectiva, as tecnologias digitais e o Origami se apresentaram como instrumentos de mediação favoráveis para ensinar e aprender Geometria. Portanto, ratificamos que o professor-formador ou o professor dos anos escolares iniciais ao fazerem escolhas tecnológicas adequadas, diversificando os recursos para promover o ensino de um determinado conteúdo matemático, potencializam a promoção da aprendizagem.

Alguns professores-alunos avançaram no conhecimento da geometria por meio da explicação oral, outros a partir da manipulação das tecnologias digitais, outros pelo manuseio do origami, ou pelas interações interpessoais. Isto é, diversificar poderá alcançar um maior número de participantes.

Por meio da experiência vivenciada os professores manifestaram alguns conhecimentos que ainda não detinham sobre os conteúdos relativos à Geometria, bem como passaram a empregar os termos científicos adequadamente. A percepção de que o ensino de Geometria não pode se resumir ao reconhecimento de figuras planas e, que é possível utilizar outros materiais e recursos para propiciar o ensino e a aprendizagem de Geometria foi, também, um dos novos significados construídos pelos professores envolvidos.

Sendo assim, há que pensar em uma formação repleta de sentidos, a qual perpasse pela valorização, respeito, interação, troca de experiências, formação em contexto de trabalho e reconhecimento da profissão docente. Ademais, colocar as narrativas de si no centro da formação, evidenciando as relações que o docente estabelece com o conteúdo matemático a ser ensinado em suas várias dimensões, pode indicar um caminho fértil para 
a tomada de consciência da docência de ontem e de hoje, a fim de prospectar a docência de amanhã.

\section{REFERÊNCIAS}

ALARCÃO, I. Professores reflexivos em uma escola reflexiva. São Paulo: Cortez, 2011.

BAGÉ, I. B. Proposta para a prática do professor do Ensino Fundamental I de noções de básicas de Geometria com usos de Tecnologias. 2008. 199 f. Dissertação (Mestrado Profissional em Ensino de Matemática). Pontifícia Universidade Católica de São Paulo (PUC/SP), São Paulo(SP), 2008.

CLANDININ, D.J; CONNELLY, F.M. Pesquisa narrativa: experiências e histórias na pesquisa qualitativa. Tradução: grupo de pesquisa narrativa e educação de professores ILEEL/UFU. Uberlândia: EDUFU, 2011.

COSTA, M. S. Discutindo o ensino de Geometria com professores Polivalentes. 2008. 145 f. Dissertação (Mestrado em Ensino de Ciências e Matemática). Universidade Cruzeiro do Sul. São Paulo(SP), 2008.

DESLAURIERS, J; KÉRISIT, M. O delineamento de pesquisa qualitativa. In: POUPART, J. et al. A pesquisa qualitativa: enfoques epistemológicos e metodológicos. Trad. Ana Cristina Nasser. Petrópolis, RJ: Vozes, 2008.

FIORENTINI, D. e MIORIM, M. A. Uma reflexão sobre o uso de materiais concretos e jogos no Ensino da Matemática. Boletim SBEM. São Paulo, v.4 n.7, p. 4-9, 1996.

FRAIHA-MARTINS, F. Significação do Ensino de Ciências e Matemática em Processos de Letramento Científico-Digital. Tese (Doutorado em Educação em Ciências e Matemáticas) - Universidade Federal do Pará, 2014.

FRAIHA-MARTINS, F. Nexos e reflexos de uma experiência formativa mediatizada por ambiente virtual de aprendizagem: formação de professores de Ciências e Matemática na Amazônia. Dissertação (Mestrado em Educação em Ciências e Matemáticas) Universidade Federal do Pará, 2009.

FREIRE, P. Pedagogia da autonomia: saberes necessários à prática educativa. São Paulo: Paz e Terra, 1996. 30 a ed.

GASPARIN, João Luiz. Uma Didática para a Pedagogia Histórico-Crítica. Campinas: Autores Associados, 2002.

IMBERNÓN, Francisco. Formação docente e profissional: formar-se para mudança e a incerteza. 9. ed. São Paulo: Cortez, 2011.

LORENZATO, S. Por que não ensinar geometria? A Educação Matemática em Revista Geometria. Blumenau, n. 4, p. 03-13, set. 1995.

MORAES, R. GALIAZZI, M.C. Análise textual discursiva. 2 ed. Ijuí: Unijui, 2011.

RÊGO, R. G. do; RÊGO, R. M.; GAUDÊNCIO, S. J. A Geometria do Origami. João Pessoa, PA: Editora Universitária/ UFPB, 2003. 
PAIVA, G. Manual de atividades no Geogebra para a educação básica. 2012. 29 f. Artigo, Taguatinga - DF, 2012.

PAVANELLO, R. M. A geometria nas séries iniciais do ensino fundamental: contribuições da pesquisa para o trabalho escolar. In: PAVANELLO, R. M. (Org.) Matemática nas séries iniciais do Ensino Fundamental: a pesquisa e a sala de aula. São Paulo: Sociedade Brasileira de Educação Matemática (SBEM), 2004. p. 129-143.

PRADO, M. E. B. B.; COSTA, N. M. L. O processo de apropriação das TIC e a reconstrução de novas práticas no ensino de matemática. In: VII Congreso Iberoamericano de Educación Matemática, 2013, Montevideo, Uruguai. VII Congreso Iberoamericano de Educación Matemática, 2013.

RODIRGUES, A. P. A. Concepções de Professores sobre a importância de se Ensinar Geometria Séries iniciais do Ensino Fundamental. 2009. 167 f. Dissertação (Mestrado em Ensino de Ciências e Matemática). Universidade Cruzeiro do Sul, São Paulo (SP), 2009.

SANTOS, C. A; NACARATO, A. M. Aprendizagem em Geometria na Educação Básica: a fotografia e a escrita na sala de aula. Belo Horizonte: Autêntica, 2014.

SAVIANI, D. Educação no Brasil: concepção e desafios para o século XXI. Revista HISTEDBR on-line, Campinas, n. 3, jul. 2001.

SAVIANI, D. Pedagogia Histórico-crítica: primeiras aproximações. 3 ed. São Paulo: Cortez: Autores Associados, 1992.

SOARES, E. S. Ensinar matemática: desafios e possibilidades. Belo Horizonte: Dimensão, 2009.

VIGOTSKI, Lev S. A formação social da mente. São Paulo: Martins Fontes, 1998.

Submetido em 30 de setembro de 2019. Aprovado em 04 de fevereiro de 2020. 